NBSIR 78-1494

Test Procedures for the

Determination of the Gross Calorific Value of Refuse and RefuseDerived-Fuels by Oxygen Bomb Calorimetry Summary of the 1977 Fiscal year Results

D. R. Kirklin, D. J. Mitchell, J. Cohen, E. S. Domalski, and S. Abramowitz

Chemical Thermodynamics Division and the

Thermal Processes Division National Bureau of Standards

Washington, D.C. 20234

December 1978

Prepared for:

U.S. Department of Energy Office of the Assistant Secretary Conservation and Solar Applications Division of Building Community Systems Urban Waste Technology Branch Washington, D.C. 20545 and

\title{
U.S. Environmental Protection Agency
} Municipal Environmental Research Laboratory Solid and Hazardous Waste Research Division - $Q C=$ Cincinnati, OH 45268 
TEST PROCEDURES FOR THE

DETERMINATION OF THE GROSS CALORIFIC

VALUE OF REFUSE AND REFUSE-

DERIVED-FUELS BY OXYGEN BOMB

CALORIMETRY

SUMMARY OF THE 1977 FISCAL YEAR

RESULTS

D. R. Kirklin, D. J. Mitchell, J. Cohen, E. S. Domalski, and S. Abramowitz

Chemical Thermodynamics Division

and the

Thermal Processes Division

National Bureau of Standards

Washington, D.C. 20234

December 1978

Prepared for

U.S. Department of Energy

Office of the Assistant Secretary

Conservation and Solar Applications

Division of Building and Community Systems

Urban Waste Technology Branch

Washington, D.C. 20545

and

U.S. Environmental Protection Agency

Municipal Environmental Research Laboratory

Solid and Hazardous Waste Research Division

Cincinnati, OH 45268

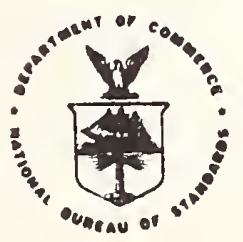

U.S. DEPARTMENT OF COMMERCE, Juanita M. Kreps, Secretary

Dr. Sidney Harman, Under Secretary

Jordan J. Baruch, Assistant Secretary for Science and Technology

NATIONAL BUREAU OF STANDARDS. Ernest Ambler, Director 
Table of Contents

Abstract $\quad 1$

Introduction $\quad 2$

Experimenta1

$\begin{array}{ll}\text { Materials } & 6\end{array}$

$\begin{array}{lc}\text { Equipment and Its Purpose } & 8\end{array}$

$\begin{array}{ll}\text { Methods } & 8\end{array}$

$\begin{array}{ll}\text { Results and Discussion } & 13\end{array}$

Calorimetric Results 13

Analytical Results 15

$\begin{array}{ll}\text { Conclusions } & 17\end{array}$

$\begin{array}{ll}\text { References } & 19\end{array}$ 



\section{List of Tables}

Table I

Benzolc Acid Calibration Results

Table. II

Calorific Values ( $\mathrm{MJ} \mathrm{kg}^{-1}$ ) for Teledyne National RDF

Table III

Calorific Values (MJ $\mathrm{kg}^{-1}$ ) for ECO-FUEL II RDF

Table IV

RDF Analyses (as determined basis)

Table V

Emission Spectrochemical Analysis of Teledyne 


\section{List of Figures}

Figure Legends

Figure 1

Schematic di.ıgram of a bomb calorimeter

Figure 2

Time-temperature curve for a bomb calorimeter

Moisture loss of an RDF sample with time

Figure 4

Moisture gain of an RDF sample with time 
TEST PROCEDURES FOR THE DETERMINATION OF THE GROSS CALORIFIC VALUE OF REFUSE AND REFUSE-DERIVED-FUELS BY OXYGEN BOMB CALORIMETRY SUMMARY OF THE 1977 FISCAL YEAR RESULTS

D. R. Kirklin, D. J. Mitche11, J. Cohen, E. S. Domalski and S. Abramowitz National Bureau of Standards Washington, DC 20234

\section{$\underline{\text { ABSTRACT }}$}

Gross calorific values have been determined for refuse-derived-fuels (RDF) from two manufacturers, Teledyne National and Combustion Equipment Associates. Test procedures used are modifications of those used for coal and coke $e^{1,2}$. The calorific values (moisture- and ash-free basis) obtained for Teledyne National RDF ranged from 24.51 to $25.20 \mathrm{MJ} \mathrm{kg}^{-1}$ (10539 to $10835 \mathrm{Btu} 1 \mathrm{~b}^{-1}$ ) with a standard deviation of 0.8 percent. The calorific values (moisture- and ash-free basis) of Combustion Equipment Associates ECO-FUEL II RDF ranged from 21.93 to $22.16 \mathrm{MJ} \mathrm{kg}^{-1}$ (9427 to $9528 \mathrm{Btu}^{-1}$ ) with a standard deviation of 0.4 percent. Results of 23 laboratory samples are presented at various stages of sample preparation which were derived from single field samples from each of the two sources. Calorimetric results based on an equilibrated laboratory sample are presented along with some semi-quantitative spectrochemical results. The results indicate that the techniques of oxygen bomb calorimetry can be successfully applied to a non-homogeneous refuse stream after considerable processing to prepare a "homogeneous" refuse-derived-fuel (RDF). 
TEST PROCEDURES FOR THE DETERMINATION OF THE GROSS CALORIFIC VALUE OF REFUSE AND REFUSE-DERIVED-FUELS BY OXYGEN BOMB CALORIMETRY

\section{SUMMARY OF THE 1977 FISCAL YEAR RESULTS}

D. R. Kirklin, D. J. Mitche11, J. Cohen, E. S. Domalski and S. Abramowitz National Bureau of Standards Washington, DC 20234

\section{Introduction}

The economic and population growth of the U.S.A. has brought about an ever-increasing problem which manifests itself through the generation of residential and commercial solid waste at an enormous rate. Our industrial, commercial, and domestic activities have made the disposal of solid waste a problem of primary concern. Landfilling and incineration are the most common methods of solid waste disposal. The disposal of solid waste in or on the land is wasteful in terms of land management and the incineration process generates large quantities of wasted energy. Moreover, landfilling and incineration can present a danger to our health and to our environment. However, useful materials can be recovered from solid waste. Paper products, metals, glass, rags, rubber and plastics can account for 50 to 80 percent of solid waste that could be available for salvage and recovery. Solid waste also represents a potential source of fuel that can be converted into energy. In addition, resource recovery from solid waste is accompanied by conservation of our natural resources. Therefore, increased interest in resource recovery from solid waste has been quite evident in recent years. 
The recovery and utilization of energy from solid waste has been the subject of much interest since much concern is being expressed about our fuel shortages. Solid waste is a potential source of fuel which can be utilized in power plant boilers to generate steam for energy purposes. Therefore, much systems development is centered around the conversion of solid waste to energy. Before solid waste can be effectively utilized in power plant boilers much testing is necessary. The areas of solid waste analysis, ash analysis, stack emission testing, corrosion testing, and boiler performance must be examined thoroughly.

The American Society of Mechanical Engineers (ASME) Committee for Performance Test Code 33-Large Incinerators (PTC-33) has indicated that a need exists to find a more accurate test procedure for the determination of calorific values of refuse and refuse-derived-fuels (RDF) which will more accurately represent a corresponding large array of collected raw refuse. If an improved calorific value test procedure is available to the ASME PTC33 Committee, it can offer a better mechanism to public works administrators and private owners by which they can evaluate whether or not their large incinerators and refuse-fired boilers are in compliance with contract performance specifications with greater accuracy and higher confidence than is currently available. The E-38 Committee on Resource Recovery of the American Society of Testing Materials (ASTM) is interested in establishing standard test methods to evaluate refuse-derived-fuels (RDF) as an article of commerce. A laboratory procedure giving reproducible results will better equip commercial laboratories to certify accurately the energy content of RDF of various compositions. As an article of commerce, RDF can be bought and 
sold as a regulated low-sulfur fuel to supplement other fossil fuels. The U.S. Department of Energy (DoE) and the U.S. Environmental Protection Agency (EPA) are collaborating in resource recovery programs to facilitate the development of various waste-to-energy technologies. The need for information on the calorific values of waste streams has been acknowledged by incinerator operators and designers for many years.

The quantity of energy liberated per unit mass of refuse burned (gross calorific value of refuse) can be directly obtained from a bomb calorimetric experiment. The techniques of bomb calorimetry have been documented and are well characterized ${ }^{1,2}$. Bomb calorimetry is used extensively in the determination of the calorific value of various fossil fuels ${ }^{3}$. Therefore, it would be extremely advantageous to be able to determine accurately the calorific values of refuse and $\mathrm{RDF}$ by bomb calorimetric methods.

However, municipal refuse is far from being an easily characterized homogeneous fuel. Its makeup can vary widely depending upon many geographical, seasonal, and weather-related factors. This variability will effect both a refuse stream's potential as a fuel source and its impact as a contributor to environmental pollution.

The objectives of this research program are three-fold:

1. Development of test procedures to determine the gross calorific value of refuse and $\mathrm{RDF}$ by bomb calorimetric methods. 
2. Evaluation of sample characteristics by analyzing for moisture, ash, carbon, hydrogen, nitrogen, sulfur and chlorine.

3. Evaluation of the homogeneity and sample preparation requirements for bomb calorimetric experiments utilizing two bomb calorimeters which have capabilities for handling samples that differ by an order of magnitude in mass (i.e. $2.5 \mathrm{~g}$ and $25 \mathrm{~g}$ ).

The small bomb calorimetric sample from a non-homogeneous refuse stream is a subject of considerable interest. A $20 \mathrm{~kg}$ (44 pound) (or larger) field sample of refuse/RDF must undergo a great deal of processing to obtain homogeneous bomb calorimetric samples. A conventional bomb calorimeter is capable of handling refuse/RDF samples of 2-3 grams in size. Therefore, development of a larger bomb calorimeter that would be capable of handling refuse/RDF samples of 20-30 grams in size is included in this research program in order to examine the effect of different types of samples (based upon degree of sample preparation) on the calorific determination of a conventional (2.5 g sample) and larger (25 g sample) bomb calorimeter.

At the outset of this research program, it was decided that the initial samples selected for characterization and calorific value determination would be RDF rather than raw refuse itself. RDF is more homogeneous, characterizable, and generally, easier to handle. Initial work on RDF would provide better insight into problems which would be encountered in handling less processed $\mathrm{RDF}$ and raw refuse. 
Refuse/RDF has five forms: (1) as-received refuse with the "white goods" removed ("white goods" are large items such as refrigerators, stoves, sinks, etc.); (2) shredded refuse of 2.5 to $7.5 \mathrm{~cm}$ (1 to 3 inch) particle size; (3) shredded refuse with most of the "heavy fraction" removed ("heavy fraction" is the non-combustibles such as glass, ceramics, metals, etc.); (4) refuse pellets; (5) refuse powder. Forms 非3, 非, and 非 are more common forms of $\mathrm{RDF}$. The sample preparation required to prepare a bomb calorimetric sample from any of the five refuse/RDF forms is such that the bomb calorimetric sample is definitely an $\mathrm{RDF}$. In fact, the preparation of a homogeneous sample for a calorific determination (regardless of the technique to be utilized) is the processing of an $\mathrm{RDF}$ of some degree. Therefore, the initial testing performed in this research project started with forms 非 and $\#_{5} 5$.

\section{Experimental}

\section{Materials}

1. Benzoic Acid. Standard Reference Material 39i was obtained from the NBS standard samples storeroom. The sample has a certified energy of combustion of $26434 \pm 3 \mathrm{~J} \cdot \mathrm{g}^{-1}$ at standard bomb conditions. All samples were drawn from the same bottle. Previous tests with benzoic acid, SRM 39i, have shown no significant differences in portions drawn from various sampling areas of the bottle.

2. Oxygen. Ultra High Purity (UHP) grade of oxygen was supplied by Matheson Gas Products. This oxygen is specified to contain combustible impurities not exceeding 0.002 percent and total impurities of less than 0.05 percent. 
3. Teledyne National $\mathrm{RDF}$. In late February 1977, a 20-kg (44 pound) sample of extruded RDF pellets was received from Teledyne National. The field sample was from the Baltimore County Resource Recovery Plant located in Cockeysville, MD. The collection of extruded pellets was contained in a cardboard box enclosed in a plastic sheet. The box of $\mathrm{RDF}$ pellets remained approximately one month in the laboratory. Thereafter, the cardboard box was taped shut with duct tape and moved to a refrigerator/freezer unit to obtain a more controllable environment.

The Teledyne National pellets are cylindrical in shape having a diameter of $2.5 \mathrm{~cm}$ ( 1 inch) and are broken-off lengths of about 2.5 to $7.5 \mathrm{~cm}$ (1 to 3 inches). The extruded pellets were broken up in an arbor press or put through a grinder and run through a micromill to yield a 10 mesh powder. The RDF was homogenized in a vee blender to provide an analysis sample. About 2.5 grams of the 10 mesh powder was placed into a pellet press (diameter, $1.59 \mathrm{~cm}$ or $0.625 \mathrm{inch}$ ) and pellets were fabricated for the bomb calorimetric experiments under approximately $10,000 \mathrm{lbs}$ of force.

4. Combustion Equipment Associates RDF. In May 1977, NBS received shipment of a 20-kg (44 pound) field sample of ECO-FUEL II RDF fuel from the Combustion Equipment Associates. The field sample was contained in a plastic bag which was twisted and taped shut. The plastic bag was enclosed in a cardboard box. The ECO-FUEL II RDF was approximately minus $425 \mu$ minus 40 mesh) particle size. The sample was placed in a controlled environment refrigerator/freezer unit. 
Equipment and Its Purpose

1. FAMCO Arbor Press. This press was necessary to fracture the extruded pellets of Teledyne National into fibrous pieces at the front end of the sample preparation.

2. Quaker City Mill, Model 4, Grinder. A grinder similar to a "sausage grinder" was necessary to break up the fibrous pieces of RDF.

3. Wylie Micro-Mill. This mill with a $1.27 \mathrm{~cm}$ (1/2 inch) diameter input throat produced a $2 \mathrm{~mm}$ (10 mesh) $\mathrm{RDF}$ sample after treatment with the larger Mode1 4 grinder.

4. Vee Blender. The vee blender was necessary to blend the $2 \mathrm{~mm}$ (10 mesh) RDF to obtain a homogeneous analysis sample of $\mathrm{RDF}$.

5. Sample Pellet Press. The combustion samples were pressed into a pellet under approximately $10,000 \mathrm{lbs}$ of force.

6. Isoperibol Oxygen Bomb Calorimeter. This is an isothermal-jacket calorimeter. The calorimeter reaction vessel is submerged in a water bath which is controlled to $\pm 0.003 \mathrm{~K}$. This prevents thermal leakage from the laboratory surroundings.

7. Quartz Oscillator Thermometer. This uses the frequency of oscillation of a temperature sensitive quartz crystal to determine the calorimeter temperature. The NBS standard frequency of $100 \mathrm{kHz}$ was utilized. Methods

1. Sample Requirements. It is necessary that a reproducible family of analysis samples be prepared from a gross field sample of refuse or refuse-derived-fuel $(\mathrm{RDF})$. The analysis sample must be representative of the field sample and unaffected by the laboratory techniques utilized to 
produce these analysis samples. In order to obtain precise calorimetric results, the analysis samples must be homogeneous. If it is assumed that the grinding and blending of the sample produces a homogeneous product, then the only constituent that must be measured and maintained is the moisture content. Therefore, the analysis samples were equilibrated in a constant humidity container maintained at the average relative humidity of the bomb calorimetric laboratory. The temperature and relative humidity of the laboratory are maintained at $295 \mathrm{~K}$ and 45 percent, respectively.

\section{Typical Sample Preparation}

a. Type I Samples. A random sample of extruded Teledyne National pellets (the laboratory sample) was removed from the field sample of RDF. The laboratory sample was weighed, milled, ground to $2 \mathrm{~mm}$ (10 mesh) and blended thoroughly. The Teledyne National sample and Combustion Equipment Associates sample (ECO-FUEL II) are, at this stage, similar in physical form. Teledyne National laboratory samples are $2 \mathrm{~mm}$ (10 mesh) while ECOFUEL II field samples were received as 425-250 im (40-60 mesh) and were not usually ground further. A series of samples may now be pressed into pellets for combustion and analysis purposes. A pellet at this stage will be described as a Type I sample. Type I pellets are equilibrated in a constant humidity atmosphere, weighed, and then dried to constant weight at $105{ }^{\circ} \mathrm{C}$ in a drying oven to form Type II pellets. The dried pellets are reweighed and the volatile content (assumed moisture) of Type I pellets can be computed. 
b. Type II Samples. Pellets which have been dried in an oven at $105^{\circ} \mathrm{C}$ are weighed and placed in a controlled constant humidity atmosphere (45 percent R.H.) for about 48 hours. The samples are then reweighed, and from the weight gain, the moisture content of the sample is calculated. Samples treated in this manner to determine moisture content are known as Type II samples.

c. Type III Samples. If the ground and blended RDF was split and blended several times before being pressed into pellets, then the RDF laboratory sample pellets are called Type III. Weighing and drying steps were performed in the same manner as for Type II samples.

In all cases, Type I, II, and III samples are equilibrated in a constant humidity (equal to the average relative humidity of the laboratory) atmosphere for approximately two days.

3. Typical Calorimetric Experiment. Bomb calorimetric techniques are well characterized and are described in detail elsewhere, but a brief description of the method which was employed in this work follows. Figure 1 shows a typical isothermally-jacketed calorimeter system ${ }^{1,2}$. In the thermochemical investigations, the heat evolved by a measured amount of RDF burned is compared with the heat evolved by a measured amount of a selected standard reaction, using a fixed calorimeter system with a substantially constant temperature rise. The standard reaction is the combustion of benzoic acid under standard bomb conditions producing a temperature rise of three degrees $(\mathrm{K})$. The energy equivalent of the calorimeter is determined from the amount of energy produced by the standard reaction and its accompanying side reactions and the corrected temperature rise. The observed temperature rise must be corrected for stirring energy and thermal leakage from the surroundings. 
Multiplication of the energy equivalent of the calorimeter by the corrected temperature rise in the RDF experiment gives the total energy produced in the RDF combustion experiment. This total energy is then corrected for the various side reactions and divided by the mass of RDF to produce the gross calorific value of $\mathrm{RDF}$. In a typical $\mathrm{RDF}$ experiment, an equilibrated RDF pellet is weighed in a weighed platinum crucible. The crucible and sample are supported inside an oxygen bomb. The sample is in contact with a $2 \mathrm{~cm}$ length of $0.076 \mathrm{~mm}$ (.003 in) wire. The bomb also contains $1 \mathrm{~cm}$ of $\mathrm{H}_{2} \mathrm{O}$ to dissolve the gaseous products of combustion and maintain an atmosphere that is saturated with water. The sealed bomb is then charged with $3.10 \mathrm{MPa}$ (30.62 atm) of high-purity oxygen. The bomb is lowered into a weighed calorimeter and the covered calorimeter is submerged in the constant temperature water bath. The calorimeter system is then heated to slightly below $25{ }^{\circ} \mathrm{C}$. Figure 2 shows a time-temperature curve for a typical bomb calorimetric experiment. The temperature is measured during the period before the sample is ignited (1ine ab in Figure 2), during the reaction period immediately after the sample is ignited (line be in Figure 2), and during the period after the reaction is complete (line eh in Figure 2). The difference between a point in the after-period and a point in the fore-period gives the observed temperature rise. The slope of the fore- and after-periods allow one to calculate the portion of the temperature rise due to stirring energy and thermal leakage. The submerged calorimeter must be stirred at a constant rate to obtain a uniform and meaningful temperature vs. time curve. A preliminary experiment was performed to determine the amount of $\mathrm{RDF}$ sample necessary to produce a three degree (K) rise in the calorimeter since our comparison reaction (benzoic acid combustion) produces a three degree (K) rise in the calorimeter. 
4. Typical Analytical Procedure. The combustion samples were weighed three times. Immediately after the pelleted laboratory samples were prepared, they were weighed to get an initial sample mass. The samples were then placed in a drying oven until they reached a constant mass. The dried samples were equilibrated in a constant humidity atmosphere until they again reached a constant mass. This data permitted a calculation of moisture content at various stages of the sample history.

After the calorimetric measurements were completed, the gaseous products were analyzed for carbon dioxide by passing the dried gaseous products through weighed absorption tubes containing successive layers of ascarite, magnesium perchlorate, and phosophorous pentoxide, each separated by a layer of asbestos fibers. The total amount of acid (nitric and sulfuric) was determined by titration of a portion of the bomb washings with a standard alkaline solution with the aid of a $\mathrm{pH}$ meter. A known amount of silver nitrate was added to a second portion of the bomb washings and the solution was titrated with ammonium thiocyanate to determine soluble chloride. Sulfur was precipitated as barium sulfate from the remainder of the bomb washings and the precipitate was weighed in order to determine the amount of sulfur.

The RDF residue remaining in the platinum crucible was weighed and elemental analysis performed using emission spectroscopy. The spectrochemical analysis were also performed on the processed (10 mesh) RDF samples. 


\section{Results and Discussion}

The primary objective of this study is to evaluate test procedures for the determination of calorific values of refuse and refuse-derived-fuels by bomb calorimetric methods. Tables I, II and III present results of combustion experiments. When using refuse or refuse-derived-fuels (RDF) as a substitute fuel, it is meaningful to analyze for the amount of moisture, ash, pollutant species, and corrosive species. These data can be found in Table IV. In addition, an elemental analysis would help to characterize the non-combustible portion of refuse and RDF. These analytical results are presented in table $\mathrm{V}$.

\section{Calorimetric Results}

Table 1 presents a summary of the results of five calibration experiments. The calibration of the calorimeter was performed with the calorimetric standard, benzoic acid (SRM 39i), which has an energy of combustion of $26434 \pm 3 \mathrm{~J} \mathrm{~g}^{-1}$ at $25^{\circ} \mathrm{C}$ and standard bomb conditions. Table I contains the amount of heat supplied to the calorimeter from the benzoic acid combustion $\left(Q_{B A}\right)$, the electrical ignition energy ( $q$-ign), the formation of nitric acid $\left(\mathrm{q}-\mathrm{HNO}_{3}\right)$, the Washburn correction to standard states $(\mathrm{q}-\mathrm{wc})$, and the correction to make the final temperature $28^{\circ} \mathrm{C}\left(\mathrm{q}-\mathrm{T}_{\mathrm{f}}\right.$ corr). The total energy supplied to the calorimeter and the corrected temperature rise are necessary to calculate the energy equivalent of the calorimeter. The energy equivalent is adjusted for the masses of the sample, the crucible and the water contained inside the bomb. The energy equivalent of the calorimeter $\left(E_{S i}\right)$ was found to be $14554.75 \mathrm{~J} \mathrm{~K}^{-1}$ at 301 K. The energy equivalent of the standard calorimeter $\left(E_{S i}\right)$ was adjusted for the heat capacities of the initial contents of the bomb to obtain the 
energy equivalent of the actual calorimeter $\left(\mathrm{E}_{\mathrm{cal}}\right)$. A heat capacity of $1 \mathrm{~J}$ $\mathrm{g}^{-1} \mathrm{~K}^{-1}$ was assumed for RDF since it is primarily cellulose. [ $\alpha$-cellulose, the chief constituent of paper pulp, has a heat capacity of $1.16 \mathrm{~J} \mathrm{~g}^{-1} \mathrm{~K}^{-1}$ at $298 \mathrm{~K}$.

The calorific data on RDF from Teledyne National and Combustion Equipment Associates are presented in tables II and III, respectively.

The calorific values are presented in three sets (as determined, moisture-free, and moisture- and ash-free). The moisture content was determined as described in the section on Methods under part $2 \mathrm{~b}$ for Type II samples prior to each calorimetric run. For Type I samples, a separate moisture determination was carried out on samples from the same batch. The calculation of the calorific values on a moisture-free (MF) basis was performed using the above moisture data. The residue found in the combustion bomb after a calorimetric experiment was used to represent the ash content of the RDF sample and was employed to compute the calorific values on a moisture- and ash-free (MAF) basis.

Three types of experimental data are presented based upon the treatment of the RDF samples. Type I samples received the minimum preparation necessary to prepare pellets for our combustion experiment. The Teledyne National RDF was received as extruded pellets and thus had to be ground and then pressed into pellets. ECO-FUEL II from Combustion Equipment Associates needed only to be pressed into a pellet. Type II and Type III samples were oven dried 
at $105{ }^{\circ} \mathrm{C}$ until a constant mass was obtained and then allowed to equilibrate with ambient room temperature and relative humidity. The temperature and relative humidity of the bomb calorimetry laboratory are maintained at $295 \mathrm{~K}$ and 45 percent, respectively. The drying and equilibration periods lasted for approxiamtely 48 hours each. The respective processes were allowed to continue undisturbed for approximately 40 hours with the sample masses periodically monitored during the last 8 hours. No attempt was made to determine the minimum time necessary for drying and equilibration. In addition, Type III samples were subjected to several splitting steps as explained in the experimental procedures (part 2c).

The moisture- and ash-free (MAF) statistical results are included in the Tables for Teledyne National and ECO-FUEL II RDF. The statistical considerations for Type I Teledyne National RDF are not meaningful since only one preliminary experiments of Type I was performed.

\section{Analytical Results}

Table IV presents the results of laboratory analyses performed as part of the calorimetric determinations. The major constituent of refuse is cellulose $\left(\mathrm{C}_{6} \mathrm{H}_{10} \mathrm{O}_{5}\right)$ which is 44.45 percent carbon (C) by mass and our measured carbon percentages are around 45 percent. The elements sulfur (S) and chlorine (Cl) are important due to their pollutant and corrosive properties. The sulfur content of the two RDF's studied was less than 1 percent (by mass). This is very good since fuel oils and coals often contain greater than 1 percent sulfur. Although the soluble chlorine results are also less than 1 percent, only small quantities of $\mathrm{HCl}$ are necessary to cause extensive corrosive damages to power generating equipment. 
The moisture and ash content greatly affect the calorific value of these fuels. Ash also presents a slagging problem in boiler operation since it must be removed from the boilers. Both $\mathrm{RDF}^{\prime} \mathrm{s}$ tested had approximately 12 percent residue. However, the most variable property is the moisture content. The deliquescent nature of $\mathrm{RDF}$ causes moisture content to vary with ambient conditions. In order to obtain reproducible data based upon moisture content, samples were equilibrated in a controlled 45 percent relative humidity atmosphere. Figures 3 and 4 are typical examples of the variability of sample mass (due to moisture content) with time during the equilibration period. Figure 3 represents a Type I sample of as-received RDF the loses moisture while equlibrating with ambient conditions $\left(22{ }^{\circ} \mathrm{C} ; 45\right.$ percent relative humidity). Figure 4 is typical of a Type II or III sample which has previously been dried and therefore picks up moisture during the equilibration period. After equilibration both Teledyne and ECO-FUEL II RDF had a moisture content of about 3.8 percent as shown in Table IV.

Spectrochemical analysis was performed on Teledyne National RDF. X-ray fluorescence spectra were recorded to identify the major elemental constituents for both RDF samples. Significant amounts of $\mathrm{Si}, \mathrm{Ca}, \mathrm{Fe}, \mathrm{Zn}, \mathrm{Ti}$, $\mathrm{Sr}$ and $\mathrm{Pb}$ were observed. Spectra of unprocessed RDF and the combustion residue of $\mathrm{RDF}$ were nearly identical with respect to the elements present. Emission spectrochemical studies were performed to give a semi-quantitative analysis of the elements. The semi-quantitative results obtained for the combustion residue of $\mathrm{RDF}$ are presented in Table V. The elements are listed in order of decreasing abundance. The approximate percentages are enclosed in parenthesis immediately following the elemental symbol. 


\section{Conclusions}

Our results on a limited number of samples have demonstrated that RDF samples can be processed for bomb calorimetric experiments to produce results with a precision (standard deviation of a measurement) approximately equal to or better than one percent. The calorific values determined for three types of sample preparation for the same RDF show no significant differences. Due to the arbitrary selection of the RDF field samples, the precision of the data obtain is a more important result, however, in no way do we suggest that the experimental results presented are typical of the average stream of the RDF's tested. For Teledyne National samples, the calorific values slightly increased with increased sample processing but opposite trends were observed for ECO-FUEL II samples. Moreover, the percent deviation (for moisture- and ash-free RDF) based on all three types of samples was $0.8 \%$ for Teledyne National RDF and $0.4 \%$ for ECO-FUEL II RDF. Percent deviations between any two sample preparation types for either Teledyne National or ECO-FUEL II ranged from 0.2 percent ECO-FUEL II to 0.9 percent, respectively.

Our standard deviations of a measurement are much less than one would initially expect for something initially as non-homogeneous as refuse or RDF. This was achieved by using the amount of combustion residue of each experiment to calculate a MAF calorific value rather than an average ash value determined by conventional ASTM procedures. For some RDF samples the ash values are not constant. Non-combustibles must "stick" to RDF particles and are therefore not uniformly distributed throughout the RDF samples. Therefore, a more precise ash-free heating value can be calculated using the amount of ash contained in each combustion sample. 
Coals of various ranks have typical moisture- and ash-free (MAF) gross heating values ${ }^{4,5}$ ranging from 34.89 to $25.59 \mathrm{MJ} \mathrm{kg}^{-1}$ (15000 to $11000 \mathrm{Btu}$ $1 \mathrm{~b}^{-1}$ ). Our MAF-RDF results ranged from 25.20 to $21.93 \mathrm{MJ} \mathrm{kg}^{-1}$ (10835 to $9427 \mathrm{Btu} 1 \mathrm{~b}^{-1}$ ). Our results are based upon two 20-kg (44 pound) field samples of RDF. It is not possible to evaluate without additional testing whether our results are typical of the RDF's produced by either manufacturer. However, the RDF's calorific value makes it definitely a viable competitor of some low rank coals. Also bituminous coals typically demand a greater degree of fineness than low rank coals to achieve complete carbon burnout ${ }^{5}$. The necessary degree of fineness for $\mathrm{RDF}^{\prime} \mathrm{s}$ may even be less (i.e. larger particles) than that for the low rank coals.

All fuels contain mineral matter that goes through varying stages of decomposition and recomposition in the combustion process. It eventually becomes either bottom ash or flyash. Coal may have ash contents of the order of 5 to 30 percent compared to the 12 percent values we experienced with RDF. However, ash fusibility data is necessary to properly evaluate the ash problem concerning refuse/RDF.

The degree of fineness required for refuse/RDF in order to obtain reproducible calorific results has not been determined. Our preliminary results were based upon a starting material of processed $\mathrm{RDF}$. We have built a larger than conventional bomb calorimeter that can handle a 20-30 gram sample of refuse/RDF. Concurrent testing of refuse/RDF samples in both our conventional size and larger size calorimeters should answer this question. 


\section{References}

1. E. J. Prosen, Experimental Thermochemistry, Chapter 6, F. D. Rossini, editor, Interscience Publishers, New York, 1956.

2. R. S. Jessup, NBS Monograph 7, 1960, Precise Measurement of Heat of Combustion with a Bomb Calorimeter, (U.S. Government Printing Office, Washington, DC 20420).

3. American Society of Testing and Materials, 1977 Annual Book of ASTM Standards, (Standards D240, D2382, D2015, and D3286), Philadelphia, PA 1977.

4. ibid, 1977 Annual Book of ASTM Standards, (Standards D388), Philadelphia, PA 1977.

5. H. E. Burbach, D. A. Harris, R. P. Hensel, O. Martinez and G. W. Thimot, Power 121, 41 (1977). 
Table I. Benzoic Acid Calibration Results

Expt. No.

\begin{tabular}{|c|c|c|c|c|}
\hline 1046 & 1047 & 1048 & 1049 & 1050 \\
\hline 26410.68 & 26410.68 & 26410.68 & 26410.68 & 26410.68 \\
\hline 1.635791 & 1.632017 & 1.650145 & 1.639178 & 1.640040 \\
\hline 43202.35 & 43102.68 & 4.3581 .45 & 43291.81 & 43314.57 \\
\hline 1.08 & 1.72 & 0.94 & 1.19 & 1.01 \\
\hline 6.80 & 5.90 & 5.77 & 5.20 & 5.30 \\
\hline 37.13 & 34.59 & 34.96 & 34.85 & 34.80 \\
\hline .02 & .04 & -.02 & .03 & .02 \\
\hline 43247.38 & 43144.93 & 43623.10 & 43333.08 & 43355.70 \\
\hline 2.969681 & 2.963055 & 2.995277 & 2.976097 & 2.977749 \\
\hline 14562.97 & 14560.96 & 14563.96 & 14560.37 & 14559.89 \\
\hline 6.87 & 6.87 & 6.89 & 6.88 & 6.88 \\
\hline 14556.10 & 14554.09 & 14557.07 & 14553.49 & 14553.01 \\
\hline \multicolumn{5}{|l|}{14554.75} \\
\hline \multicolumn{5}{|c|}{$1.72(0.012 \%)$} \\
\hline $0.78(0 . c$ & & & & \\
\hline
\end{tabular}


Table II. Calorific Values/(MJ kg $\left.{ }^{-1}\right)^{a}$ for Teledyne National RDF

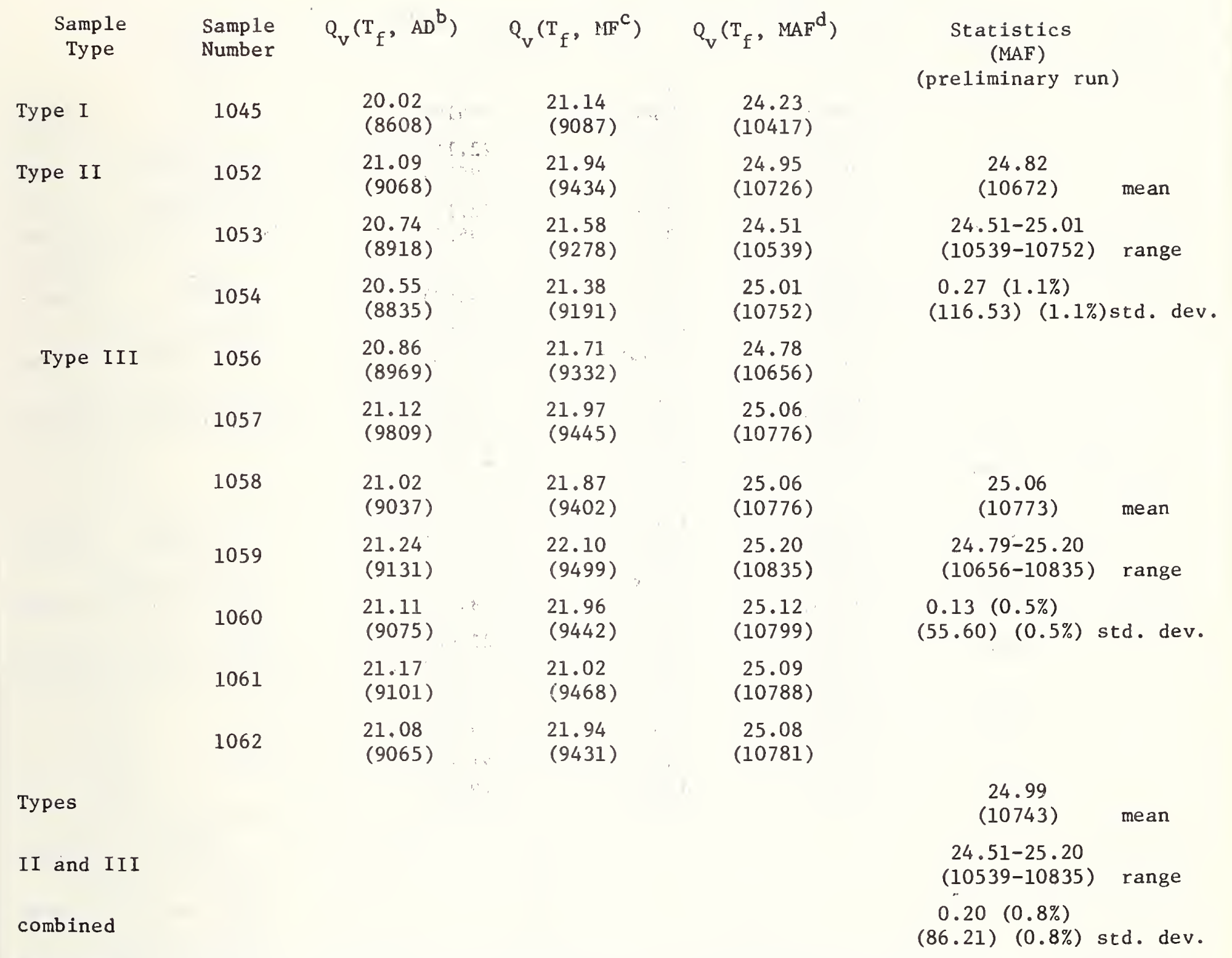

${ }^{a} \mathrm{MJ} \mathrm{kg}^{-1}=429.9226 \mathrm{Btu} 1 \mathrm{~b}^{-1}$ was used to calculate the Btu $1 \mathrm{~b}^{-1}$ values presented in parenthesis. ${ }^{b} A D=A s$ determined. $\quad c_{M F}=$ Moisture-free $\quad d_{M A F}=$ Moisture- and Ash-free 
Table III. Calorific Values/(MJ kg $\left.{ }^{-1}\right)^{a}$ for ECO-FUEL II RDF

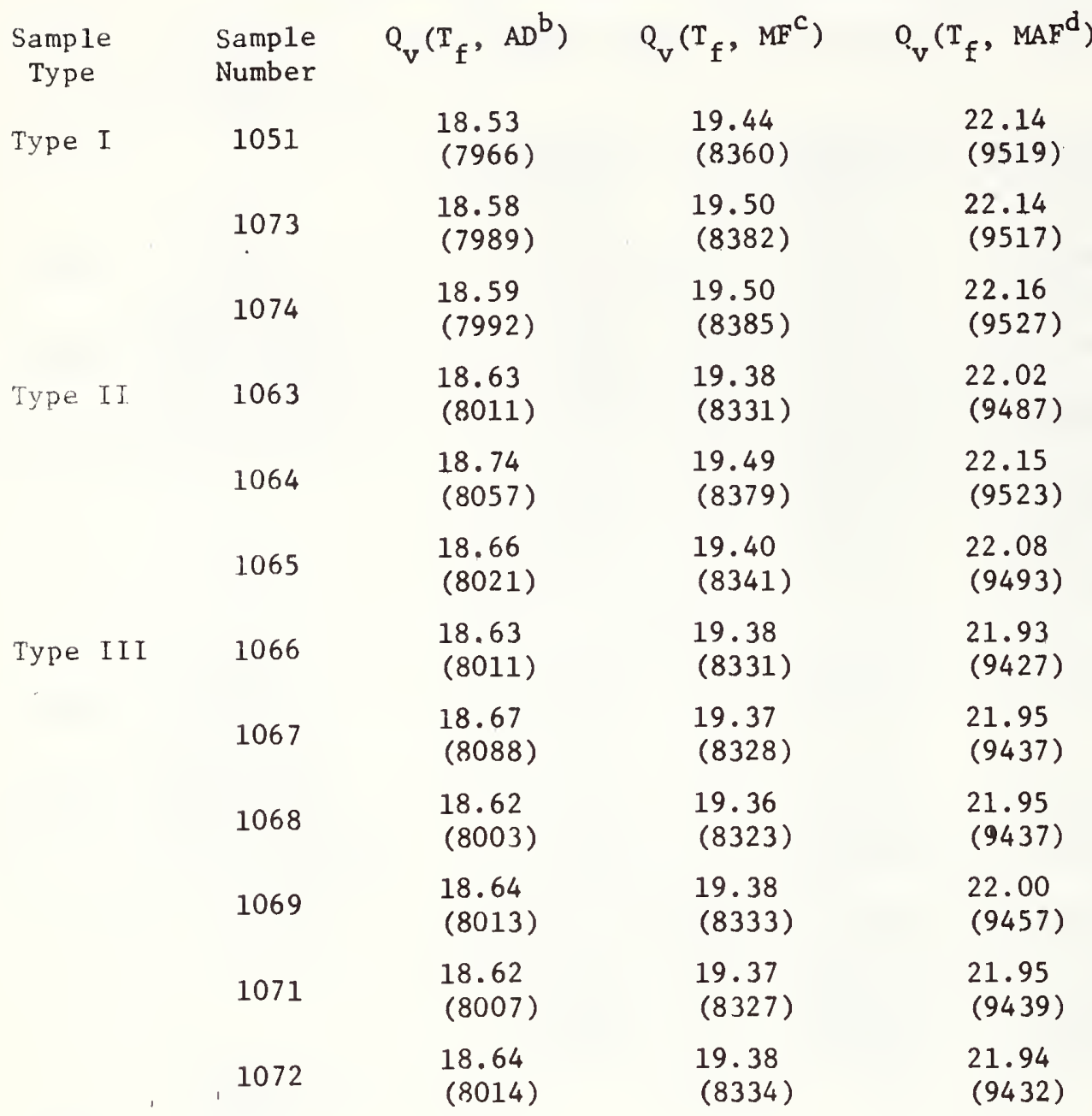

Types I, 22.04 (9475) mean

II and III

21.93-22.16 (9427-9528) range

combined

$0.09 \quad(0.4 \%)$ $(40.17)(0.4 \%)$ std. dev. ${ }_{1} \mathrm{MJ} \mathrm{kg}^{-1}=429.9226 \mathrm{Btu} 1 \mathrm{~b}^{-1}$ was used to calculate the Btu $1 \mathrm{~b}^{-1}$ values presented in parenthesis. ${ }_{A D}=$ As determined. $\quad c_{M F}=$ Moisture free. $\quad d_{M A F}=$ Moisture- and Ash-free. 
Table IV. RDF Analyses (as determined basis)

A. Teledyne National, RDF

\begin{tabular}{|c|c|c|c|c|c|}
\hline Expt. No. & $\% \mathrm{C}$ & \% Moisture & $\%$ Residue & $\%$ Sulfur & \%Chlori \\
\hline 1045 & $-\cdots$ & 5.26 & 12.08 & ---- & ---- \\
\hline 1052 & $-\cdots$ & 3.74 & 11.57 & 0.10 & ---- \\
\hline 1053 & $-\infty-\infty$ & 4.15 & 11.50 & 0.10 & ---- \\
\hline 1054 & $-\infty-\infty$ & 3.75 & 13.95 & 0.10 & --- \\
\hline 1056 & 45.94 & 3.89 & 11.94 & 0.12 & 0.23 \\
\hline 1057 & $-\cdots$ & 3.82 & 11.87 & ---- & --- \\
\hline 1058 & $-\cdots$ & 3.85 & 12.25 & 0.12 & 0.21 \\
\hline 1059 & $---\infty$ & 3.88 & 11.84 & 0.12 & 0.25 \\
\hline 1060 & ---- & 3.83 & 12.08 & 0.11 & 0.20 \\
\hline 1061 & $-\infty$ & 3.96 & 11.76 & 0.12 & 0.17 \\
\hline 1062 & 45.99 & 3.93 & 12.04 & 0.12 & 0.18 \\
\hline Mean & 45.97 & 3.88 & 12.08 & 0.11 & 0.21 \\
\hline Std. Dev. & 0.04 & 0.113 & 0.66 & 0.01 & 0.03 \\
\hline$\%$ Std. Dev. & 0.08 & $3.04 \%$ & 5.46 & 8.66 & 14.57 \\
\hline
\end{tabular}

B. Combustion Equipment Associates, ECO-FUEL II RDF

\begin{tabular}{|c|c|c|c|c|c|}
\hline 1051 & $\cdots-$ & 4.69 & 11.60 & 0.474 & .326 \\
\hline 1073 & $-\cdots$ & 4.69 & 11.32 & .476 & .317 \\
\hline 1074 & $-\cdots$ & 4.69 & 11.36 & .502 & .334 \\
\hline 1063 & $---\infty$ & 4.00 & 11.43 & .522 & .369 \\
\hline 1064 & $-\infty-\infty$ & 3.68 & 11.72 & .514 & .331 \\
\hline 1065 & 44.35 & 4.10 & 11.55 & .494 & .345 \\
\hline 1066 & $-\infty-\infty$ & 3.88 & 11.67 & .488 & .368 \\
\hline 1067 & $-\cdots$ & 3.82 & 11.19 & .486 & .341 \\
\hline 1068 & --- & 3.85 & $11 \cdot 30$ & .496 & .381 \\
\hline 1069 & $--\infty$ & 3.55 & 11.36 & .493 & .352 \\
\hline 1071 & $\cdots$ & 3.79 & 11.43 & .479 & .352 \\
\hline 1072 & $-\infty$ & 3.86 & 11.20 & .480 & .352 \\
\hline Mean & $\infty-\infty$ & $3.8 \dot{4}$ & 11.43 & 0.492 & 0.347 \\
\hline Std. Dev. & $-\cdots-$ & 0.16 & 0.17 & 0.015 & 0.019 \\
\hline \%Std. Dev. & ---- & 4.20 & 1.53 & 3.03 & 5.46 \\
\hline
\end{tabular}


Table V. Emission Spectrochemical Analysis of Teledyne National RDF Residue

$$
\% \geq 1
$$

Si (50)

$\mathrm{Ca}$ (15)

$\mathrm{Na}(10)$

Al ( 5)

Fe ( 2)

Zn ( 2)

K ( 2)

Mg ( 1)

Ti (1)
$1>\% \geq .1$

Mn (.5)

$\mathrm{Ba}(.2)$

Sr $(.2)$

Cr (.1)

$\mathrm{Pb}(.1)$

Sn (.1)

$.1>\% \geq .01$

Li (.05)

$\mathrm{Cu}(.04)$

Cd (.02)

Ni (.02)

$\mathrm{V} \quad(.02)$

$\operatorname{Zr}(.02)$

B $(.01)$

Mo (.01)

$\mathrm{Rb}(.01)$ 


\section{FIGURE LEGENDS}

Figure 1. Schematic diagram of a bomb calorimeter.

A water bath jacket, B water bath, C submarine vessel, D calorimeter vessel, E temperature sensor, $F$ air space, G bomb, $\mathrm{H}$ calorimeter heater, I direction of water flow, J water in calorimeter vessel, $\mathrm{K}$ thermoregulator, $\mathrm{L}$ calorimeter stirrer, $M$ bath stirrer, $\mathrm{N}$ bath heater.

Figure 2. Time-temperature curve for a bomb calorimeter experiment.

$t_{i}$ initial time of an experiment, $t_{b}$ time at which main reaction period begins, commenced by ignition of sample, $t_{x}$, mid-time determined graphically to calculate the cooling correction, $t_{e}$ time at which main reaction period ends, $t_{f}$ final temperature of an experiment, $\theta_{i}$ initial temperature of an experiment, $\theta_{f}$ final temperature of an experiment $\theta_{j} j$ acket temperature (i.e.) temperature of water bath), $\theta_{\infty}$ convergence temperature (i.e., temperature which the calorimeter would attain in an infinite time if $\theta_{j}$ and the rate of stirring remain constant.

Figure 3. Moisture loss of an $\mathrm{RDF}$ sample with time.

Moisture loss exhibited by a Type I sample.

Figure 4. Moisture gain of an RDF smaple with time.

Moisture gain exhibited by a Type II or Type III sample. 
FIGURE 1

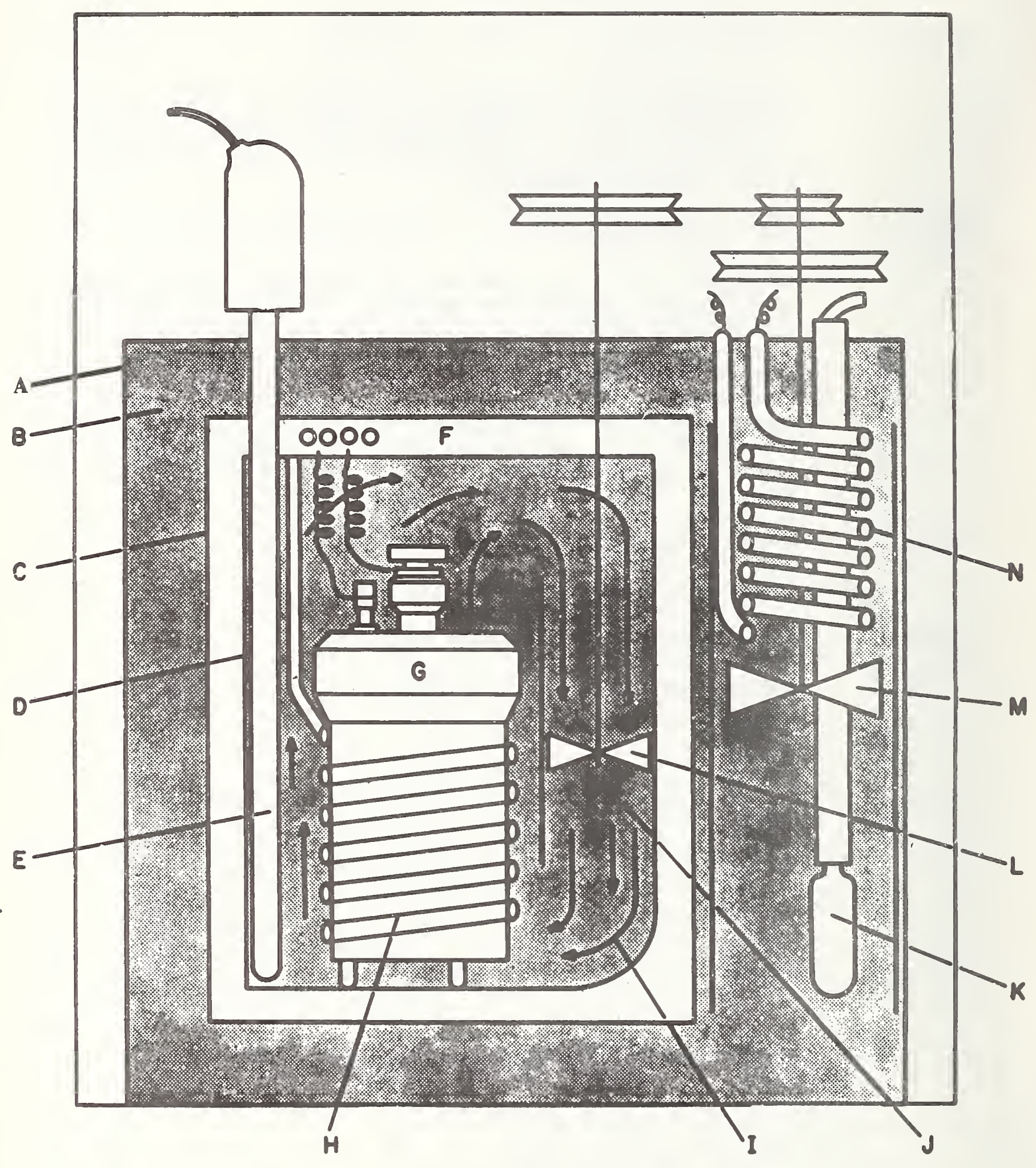


FIGURE 2

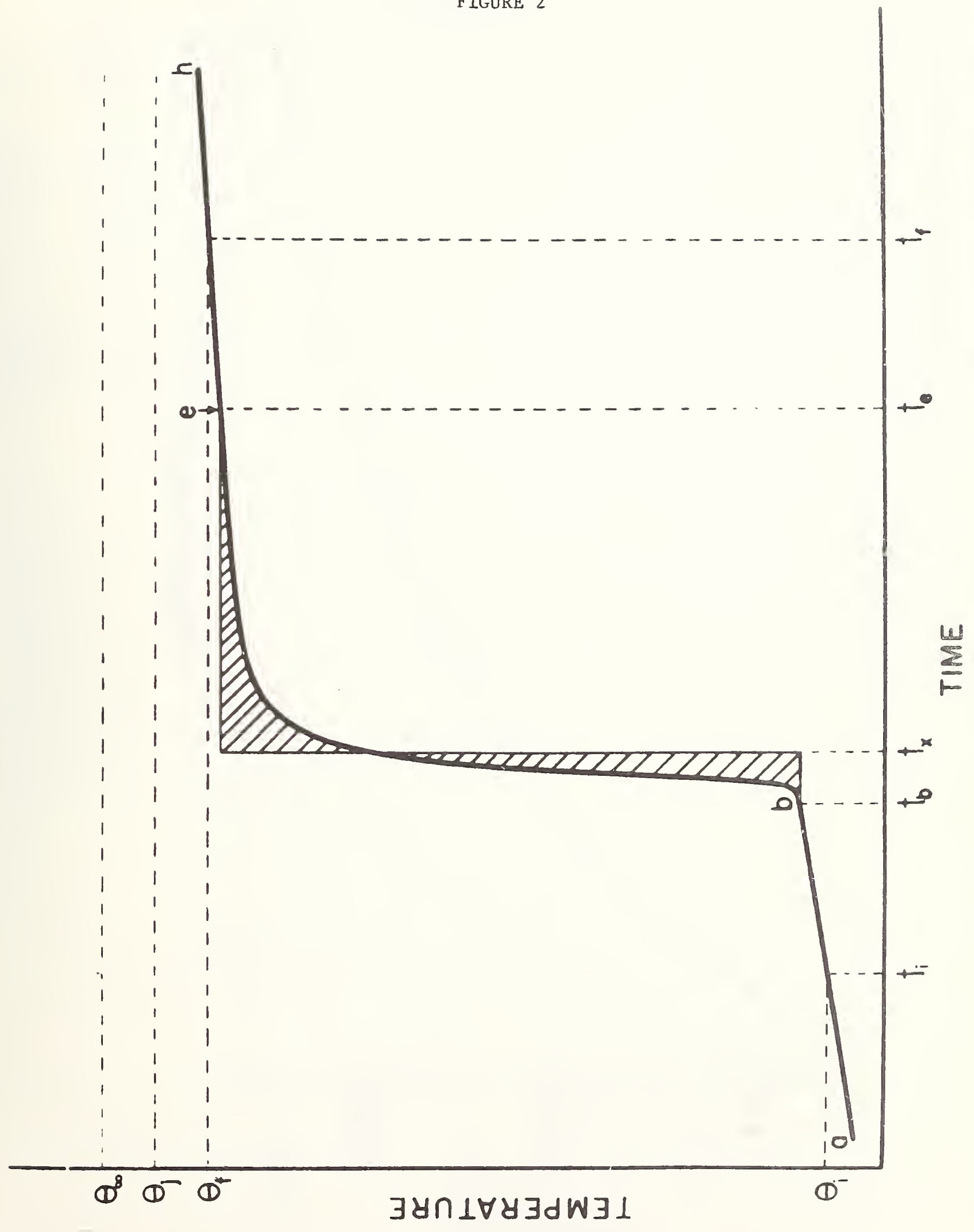




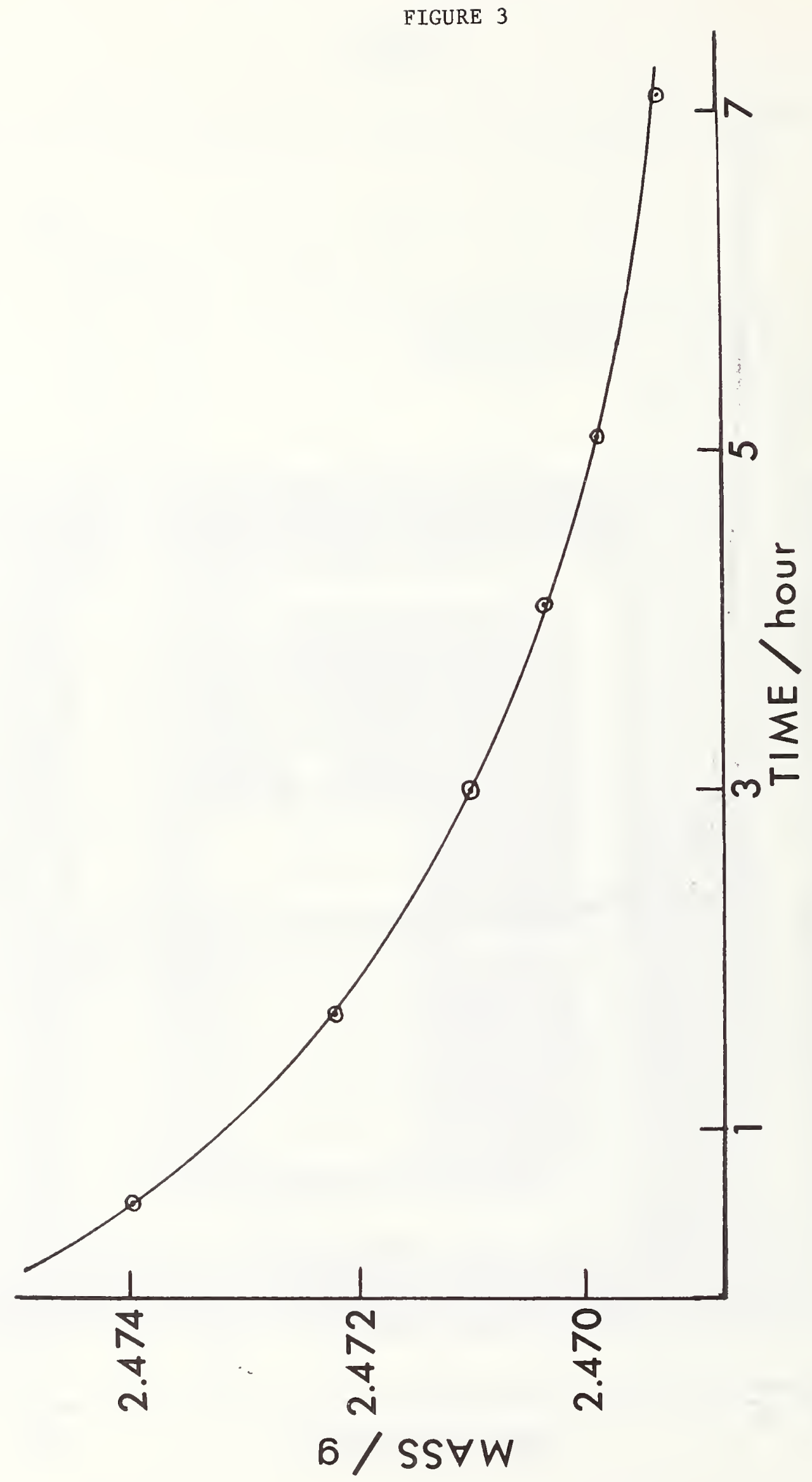


FIGURE 4

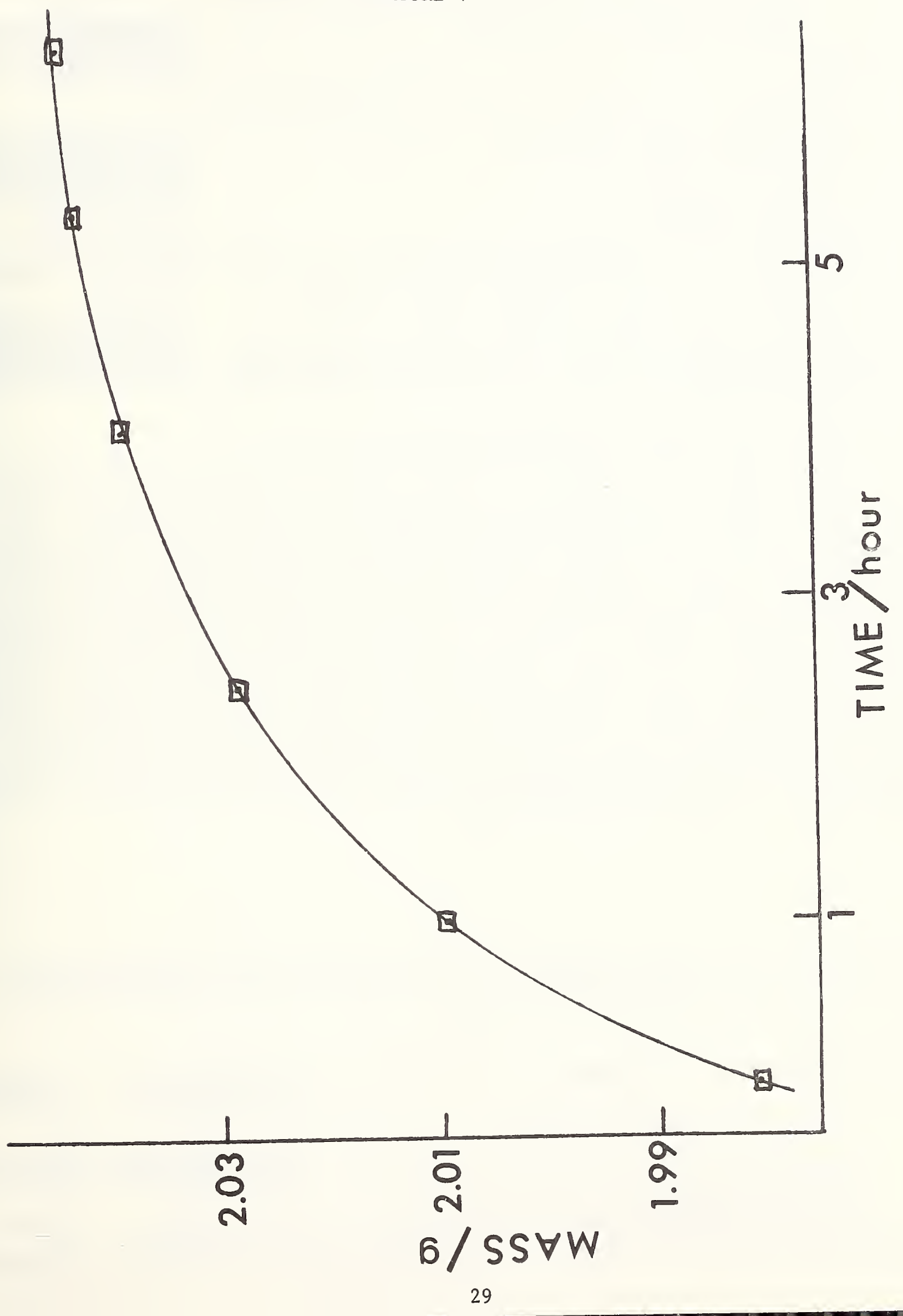


NBS.114A (REV. 9.78)

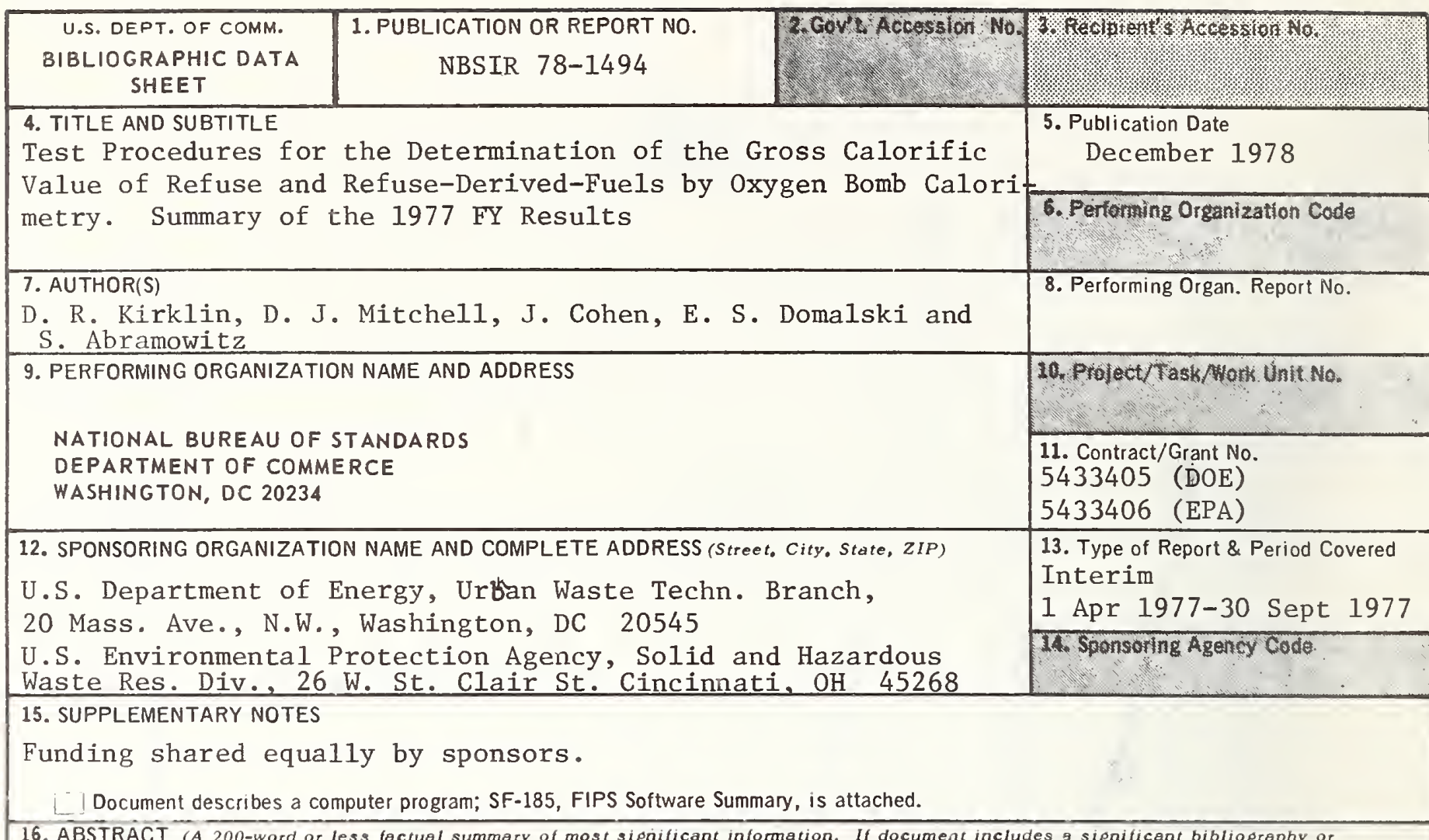

16. ABSTRACT (A 200-word or less factual summary of most significant information. If document includes a significant bibliography or literature survey, mention it here.)

Gross calorific values have been determined for refuse-derived-fuels (RDF) from two manufacturers, Teledyne National and Combustion Equipment Associates. Test procedures used are modifications of those used for coal and coke ${ }^{1,2}$. The calorific values (moisture- and ash-free basis) obtained for Teledyne National RDF ranged from 24.51 to

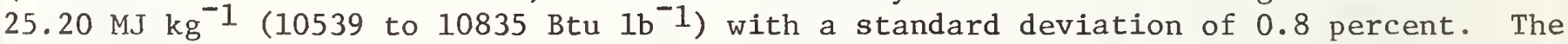
calorific values (moisture- and ash-free basis) of Combustion Equipment Associates

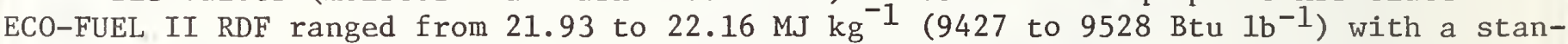
dard deviation of 0.4 percent. Results of 23 laboratory samples are presented at various stages of sample preparation which were derived from single field samples from each of the two sources. Calorimetric results based on an equilibrated laboratory sample are presented along with some semi-quantitative spectrochemical results. The results indicate that the techniques of oxygen homb calorimetry can be successfully applied to a non-homogeneous refuse stream after considerable processing to prepare a "homogeneous" refuse-derived-fuel (RDF).

17. KEY WORDS (six to twelve entries; alphabetical order; capitalize only the first letter of the first key word unless a proper name; separated by semicotons) Bomb calorimetry; gross calorific values; refuse-derived-fuels; sample characterization; test procedures.

IX Order From National Technical Information Service (NTIS), Springfield, VA. 22161

\begin{tabular}{|l|c|}
\hline $\begin{array}{l}\text { 19. SECURITY CLASS } \\
\text { (THIS REPORT) }\end{array}$ & $\begin{array}{c}\text { 21. NO. OF } \\
\text { PRINTED PAGES } \\
\text { UNCLASSIFIED }\end{array}$ \\
\hline $\begin{array}{l}\text { 20. SECURITY CLASS } \\
\text { (THIS PAGE) }\end{array}$ & 34 \\
UNCLASSIFIED & $\$ 4.00$ \\
\hline
\end{tabular}




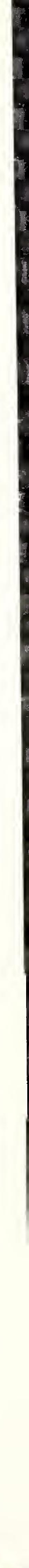




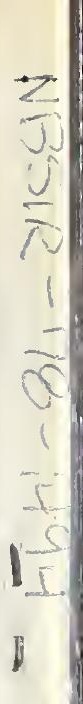

i

) 